\title{
Políticas públicas na promoção da sucessão familiar no meio rural: avaliação das organizações sociais do oeste catarinense
}

\author{
Ana Paula Grando ${ }^{1}$ \\ Márcia Luiza Pit Dal Magro ${ }^{2}$ \\ Rosana Maria Badalotti ${ }^{3}$
}

\begin{abstract}
Resumo: Dados apontam que a saída do jovem do meio rural segue sendo uma ameaça para reprodução social da agricultura familiar, bem como para as organizações sociais que a representam. Essa situação implica na necessidade de construção de políticas que envolvam os processos sucessórios. Esta pesquisa teve como objetivo geral analisar como as organizações sociais representativas da agricultura familiar situadas no oeste do estado de Santa Catarina avaliam os efeitos das políticas públicas para a sucessão familiar no meio rural. O método utilizado foi o da pesquisa qualitativa, em que foram realizadas doze entrevistas semiestruturadas e pesquisa documental. Participaram da pesquisa nove organizações sociais da agricultura familiar, um pesquisador e uma empresa pública. Como resultados pode-se identificar a importância dos espaços de representação social da agricultura familiar como articuladoras e provedoras de políticas públicas. Entre as políticas existentes foram destacadas as voltadas ao crédito e assistência técnica. As organizações sociais passaram a ser operadoras das políticas desenvolvendo um papel mais técnico-operacional do que político-organizativo. Apesar dos avanços das políticas voltadas à agricultura familiar nos últimos 20 anos, e da presença de diversas organizações sociais voltadas à agricultura familiar na região, essas ainda estão desarticuladas e restringem-se às ações pontuais, não promovendo efetivamente a sucessão familiar.
\end{abstract}

Palavras-chave: Agricultura familiar. Organizações sociais rurais. Políticas públicas. Sucessão familiar.

Abstract: Data indicate that the exit of rural youth continues to be a threat to the social reproduction of family agriculture, as well as to the social organizations that represent it. This situation implies the need to construct policies that involve succession processes. This research had as general objective to analyze how the representative social organizations of the family agriculture located in the west of the state of Santa Catarina evaluate the effects of the public politics for the family succession in the rural environment. The method used was qualitative research, in which twelve semi-structured interviews and documentary research were carried out. Nine social organizations of family agriculture, a researcher and a public company participated in the research. As results one can identify the importance of social representation spaces of family agriculture as articulators and providers of public policies. Among the existing policies were those focused on credit and technical assistance. Social organizations became policy makers by developing a more technical-operational rather than political-organizational role. Despite advances in family farming policies over the past 20 years, and the presence of various social organizations focused

${ }^{1}$ Mestre em Políticas Sociais e Dinâmicas Regionais. aninhagrando@hotmail.com

2 Doutora em Psicologia Social. Professora do Programa de Pós-Graduação em Políticas Sociais e Dinâmicas Regionais da Universidade Comunitária da Região de Chapecó (Unochapecó/SC).mapit@unochapeco.edu.br

${ }^{3}$ Doutora em Ciências Humanas. Professora do Programa de Pós-Graduação em Políticas Sociais e Dinâmicas Regionais da Universidade Comunitária da Região de Chapecó (Unochapecó/SC). rosana@unochapeco.edu.br 
on family agriculture in the region, these are still disjointed and are restricted to specific actions, not effectively promoting family succession.

Keywords: Family farming. Rural social organizations. Public policy. Family succession.

\section{Introdução}

As questões que envolvem a sucessão ${ }^{1}$ na agricultura familiar têm sido amplamente debatidas pela academia, pelo Estado e pelas organizações sociais que a representam. Centralmente a este debate está colocada a necessidade e a dificuldade de encontrar sucessores nos empreendimentos rurais de base familiar, comprometendo a produção de alimentos no Brasil e colocando em risco a continuidade de um projeto sociopolítico e de reprodução sociocultural (RENK, 2000).

Dados dos censos populacionais apresentam que em 1940 a população rural correspondia a 68,7\% da população total e, em 2010 a 15,64\%, o que representa uma diminuição de 53,06\% da população rural brasileira em 70 anos. O Censo realizado em 2010 aponta que em um período de dez anos 800.000 jovens no Brasil deixaram o meio rural e migraram para o espaço urbano, buscando empregabilidade e estudo (IBGE, 2010).

Nos últimos 20 anos têm avançado as pesquisas e debates que tratam dos padrões sucessórios na agricultura familiar, dos quais são exemplos as obras de Abramovay (1998), Silvestro et al (2001) e Castro (2005). Estes debates têm dialogado com processos e mudanças mais amplas que ocorreram "[...] no cenário político institucional e nas dinâmicas sociais nos últimos 20 anos no Brasil”, segundo Grisa e Schneider (2015, p. 126).

Este processo têm configurado no âmbito das políticas públicas novas relações entre Estado e sociedade civil, espaços de participação, formulação e execução de políticas emergiram destas relações com destaque para o protagonismo de atores sociais, entre eles “[...] a agricultura familiar, uma categoria social e política que passou a ser reconhecida pelo Estado brasileiro em meados de 1990" (GRISA E SCHNEIDER, 2015, p. 126). Considerando este processo, desde meados dos anos 1990, de acordo com Grisa e Schneider (2015, p.141), construiu-se um marco regulatório para a agricultura familiar em que foram criadas e 
executadas “[...] um amplo espectro de políticas públicas direcionadas para a agricultura familiar".

O debate acadêmico e a agenda política direcionada especificamente para a juventude rural foram configuradas segundo Barcelos (2017) a partir dos anos 2000, como decorrência de reflexões sobre a realidade dessa população, tais como o êxodo, ausências de políticas públicas, o envelhecimento do campo, a sucessão familiar, entre outras temáticas relacionadas.

No que se refere a problemática deste artigo, possuem interface com a sucessão familiar, ações e programas ministeriais e interministeriais, a exemplo, do Pronaf Jovem e o selo Nossa Primeira Terra (NPT), este último vinculado ao Programa Nacional de Crédito Fundiário (PNCF) formulados e implementados a partir de 2004; o Programa Nacional de Acesso ao Ensino Técnico e Emprego (Pronatec Campo) lançado e implementado a partir de 2011 e mais recentemente o Plano Nacional de Juventude e Sucessão Rural, formulado e lançado em 2016, segundo Barcelos (2017).

Apesar das diferentes ações desenvolvidas para a agricultura familiar e em especial a partir das ações específicas para os jovens rurais, a permanência do jovem no campo continua se apresentando como um desafio. Pesquisas apontam que em Santa Catarina, 30\% das propriedades rurais não tem perspectiva de sucessores, o que acarretará em diminuição do número de empreendimentos e concentração da produção e da riqueza. (SILVESTRO, 2001). Ainda é possível identificar nas pesquisas de Renk e Dorigon (2014) que as transformações econômicas, sociais e políticas nos padrões sucessórios impactam na escolha do jovem pela saída do rural.

A agenda política é vital quando nos referimos à sucessão como uma dimensão importante para a reprodução da agricultura familiar, pois, a partir dela entende-se em que medida as pautas e reivindicações dos agricultores vêm se construindo e consolidando, a partir da atuação das diferentes organizações que representam este universo. Portanto, pensar a problemática da sucessão familiar no meio rural implica também em articular as principais dificuldades encontradas para que ela aconteça, desenvolvendo ações e políticas públicas para promover a melhoria das condições de vida dos agricultores.Tendo em vista a problemática apresentada, esse texto analisa como as organizações sociais representativas da agricultura 
familiar que atuam na região Oeste do Estado de Santa Catarina avaliam os efeitos das políticas públicas para a sucessão familiar no meio rural ${ }^{2}$.

O texto está organizado em uma primeira seção em que são apresentados os procedimentos metodológicos adotados na pesquisa, que é de cunho qualitativo. Na sequência aborda-se brevemente as políticas públicas voltadas à agricultura familiar e seus efeitos para a sucessão no meio rural, com ênfase para duas políticas públicas que foram destacadas pelas organizações sociais participantes do estudo, sendo elas as políticas de crédito e a assistência técnica.

\section{Metodologia}

A presente pesquisa, de cunho qualitativo, foi realizada predominantemente com organizações sociais representativas da agricultura familiar com atuação no Oeste do Estado de Santa Catarina. Estas foram delimitadas considerando como critério de inclusão sua atuação em lutas históricas da agricultura familiar na região, priorizando as que possuem uma base político organizativa semelhante.

Para o alcance do objetivo proposto, inicialmente foi realizada uma pesquisa exploratória a fim de mapear os órgãos governamentais, organizações e movimentos sociais representativos da agricultura familiar na região em foco. A partir desta, foram mapeadas nove organizações representativas da agricultura familiar que compuseram essa pesquisa: Movimento das Mulheres Camponesas (MMC); União Nacional das Cooperativas da Agricultura Familiar e Economia Solidária (Unicafes); Cooperativa Central Sabor Colonial; Federação dos Trabalhadores na Agricultura Familiar da Região Sul (Fetraf Sul); Sindicato dos Trabalhadores na Agricultura Familiar de Chapecó e Região (Sintraf Chapecó); Movimento dos Trabalhadores Rurais Sem Terra (MST); Associação dos Pequenos Agricultores do Oeste Catarinense (APACO); Cooperativa Central de Crédito Rural com Interação Solidária (Cresol Central SC/RS); Cooperativa Central de Tecnologia, Desenvolvimento e Informação (Coopertec). Também foram inseridos na pesquisa um pesquisador com produção acerca da temática da sucessão familiar na região e a Empresa de Assistência Técnica e Extensão Rural - Epagri. 3 Os instrumentos e 
técnicas utilizados na pesquisa foram pesquisa documental e entrevistas com roteiro semiestruturado. A pesquisa documental ocorreu primeiramente nos materiais disponíveis nos sites de acesso público das organizações. Também foram analisados materiais de políticas públicas e documentos das organizações sociais participantes da pesquisa para compreender sua organização, objetivos e processo histórico de constituição.

Foram realizadas 11 entrevistas semiestruturadas com representantes das organizações sociais, órgãos de pesquisa e pesquisador mapeados, as quais ocorreram entre os meses de maio a setembro de 2015. Foram critérios para inclusão dos informantes, serem representantes com cargos executivos nas organizações selecionadas, ter papel diretivo e ter participado de projetos e ações organizativas e políticas da agricultura familiar.

Para condução da pesquisa foi observado o disposto na Resolução $n^{\circ} 466$ de 12 de dezembro de 2012, do Conselho Nacional de Saúde e do Comitê de Ética em pesquisa da Unochapecó que aprova as diretrizes e normas reguladoras de pesquisa envolvendo humanos ${ }^{1}$.

As informações foram analisadas por meio da análise temática de conteúdo descrita por Minayo (2010). Entre as categorias levantadas por meio da análise, esse artigo se deterá na apresentação de duas que são: as principais políticas públicas que possuem interfaces no apoio a sucessão familiar e as novas e velhas pautas das organizações sociais para a agricultura familiar e a promoção da sucessão.

\section{As políticas públicas voltadas à agricultura familiar e seus efeitos para a sucessão no meio rural}

No Brasil, de acordo com Grisa e Schneider (2015), as políticas públicas voltadas à agricultura familiar apresentam três "gerações" ou referenciais "[...] fortalecidos em alguns momentos-chaves, o modo como estes referenciais foram construídos, e as relações entre Estado e sociedade civil". O primeiro iniciou na segunda metade da década de 1960, e foi orientado pela modernização tecnológica da agricultura. 
O ajuste entre o setor da agricultura ("referencial setorial") e a industrialização da economia do País ("referencial global") passou a ser realizado por um conjunto de ações e políticas públicas, como crédito rural, garantia de preços mínimos, seguro agrícola, pesquisa agropecuária, assistência técnica e extensão rural, incentivos fiscais às exportações, minidesvalorizações cambiais, subsídios à aquisição de insumos, expansão da fronteira agrícola, e o desenvolvimento de infraestruturas. (GRISA, SCHNEIDER, 2015, p. 129)

Já na década de 1990, sob a égide do neoliberalismo, o segundo referencial que orienta as políticas públicas está voltado ao combate da pobreza rural a fim de "corrigir as falhas de mercado", por meio de ações sociais e assistenciais, das quais são exemplo o Programa Comunidade Solidária e o Programa Fome Zero, implementado durante o governo Lula.

Nos anos 2000, o terceiro referencial abre espaço para políticas públicas voltadas à segurança alimentar e nutricional e para a sustentabilidade, com destaque para temas como agroecologia, em que há o protagonismo de movimentos sociais, estudiosos e políticos vinculados a partidos de esquerda. Nesse contexto, as organizações sociais que se originaram das lutas dos agricultores também passaram a ser operadoras das políticas públicas voltadas para este público. (GRISA, SCHNEIDER, 2015, p. 132)

Entre as políticas criadas a partir dos anos de 1990, merece destaque o Programa Nacional de Fortalecimento da Agricultura Familiar (Pronaf) implementado em 1997, este programa se situa na $2 \underline{a}$ geração de políticas para a agricultura familiar e na ${ }^{3}$ a geração cujo referencial está voltado para a construção de mercados para segurança alimentar e sustentabilidade ambiental, se destacam o Programa de Aquisição de Alimentos (PAA), o Programa Nacional de Alimentação Escolar (PNAE) entre outros, criados e implementados a partir de 2003, segundo Grisa e Schneider (2015).

Castro (2016) ao apresentar os avanços das ações realizadas de 2005 a 2015, para a juventude rural pelos governos Lula e Dilma, afirma que apesar das importantes conquistas nos marcos legais, na formação de institucionalidades e formulação de políticas públicas, estas se circunscreveram a esses governos, porém tais avanços não se consolidaram em políticas de Estado. Por outro lado, a autora afirma que a diversidade da juventude brasileira não se capilarizou nas múltiplas ações do próprio governo federal nesses 10 anos, pois não foi possível consolidar uma política nacional para a juventude rural e um Plano Nacional de Juventude e 
Sucessão Rural. Um aspecto central nesta discussão estrutural que a autora propõe é sobre a priorização de um projeto de Agricultura Familiar que inclua a soberania alimentar como um dos seus pilares e que tenha como centro a juventude. Outra questão prioritária é a reforma agrária e uma profunda mudança na estrutura fundiária brasileira.

Apesar dos avanços e ampliação de políticas públicas voltadas à agricultura familiar, ao longo das últimas décadas, a problemática da sucessão nos espaços rurais se constitui em uma preocupação recente na agenda pública enquanto política pública específica e estratégia estrutural. Segundo Barcellos (2017), em 2016 foi formulado e lançado o Plano Nacional de Juventude e Sucessão Rural, fruto de uma oficina realizada pelo MDA e que agregou pautas apontadas pelos movimentos sociais como a ausência de políticas estruturantes para as juventudes do campo, das águas e das florestas. Este plano se orienta por cinco diretrizes: a garantia dos direitos sociais e da juventude; a garantia de acesso aos serviços públicos e às atividades produtivas com geração de renda e promoção do desenvolvimento sustentável e solidário; o estímulo e o fortalecimento das redes da juventude nos territórios rurais; a valorização das identidades e diversidade individual e coletiva da juventude rural; a atuação transparente, democrática, participativa dos órgãos da administração pública federal com os governos estaduais, distrital e municipais, e com a sociedade. Em relação as políticas em vigência, duas se destacaram como fundamentais para a permanência do agricultor no meio rural e à promoção da sucessão familiar na pesquisa realizada, tendo ainda estreita relação com as organizações investigadas. As políticas destacadas pelas organizações investigadas estão voltadas ao crédito agrícola e à assistência técnica e serão discutidas a seguir.

\subsection{O papel do PRONAF e do crédito Fundiário para promover a sucessão da AF}

No que diz respeito às políticas públicas identificadas na pesquisa e que contribuem para promover a permanência do agricultor no meio rural, os entrevistados ressaltaram que o Pronaf possui um papel importante. O programa foi constituído em 1996, e tem como objetivo o financiamento de projetos individuais ou coletivos, em 12 linhas de crédito com menores juros comparando aos praticados pelo mercado financeiro, a fim de financiar o processo produtivo do 
meio rural. É um programa de crédito que impactou diretamente a capacidade de produção e melhora da qualidade de vida e empregabilidade no meio rural (BIANCHINI, 2015).

Antes da criação do Pronaf os entrevistados relatam que existiam outras formas de financiamento da produção agrícola, por meio das organizações sociais que criaram os fundos rotativos de crédito 4 . O sentido do crédito solidário se dá na origem e destino dos recursos aplicados nas propriedades, conhecido como fundo solidário. Nesse sistema, o recurso de quem aplica em capital social ou depósito a prazo nas cooperativas de crédito torna-se crédito para o agricultor que não tinha acesso no sistema creditício tradicional. O juro aplicado no crédito era utilizado para a manutenção das cooperativas e revertia em mais crédito.

Fruto da luta da base organizativa, o Pronaf foi discutido em 1993 em um seminário em Chapecó (SC), que identificou a necessidade de crédito como uma das mais importantes para a reprodução da agricultura familiar, a qual ainda foi reiteradamente discutida pelo "Grito da Terra" no período de 1990. (BIANCHINI, 2015). O Programa se consolidou como uma importante política de crédito, aliada a ações de organização da produção, seguro agrícola, assistência técnica, com uma grande cobertura e acesso no território brasileiro. Este programa atua em 4963 municípios através dos agentes financeiros fiscalizados pelo Banco Central do Brasil e credenciados pelo Tesouro Nacional, tais como Banco do Nordeste Brasileiro (BNB), Banco Nacional do Desenvolvimento Sustentável (BNDES), Banco do Brasil (BB) e outros (MDA, 2016).

Nos 20 anos de programa foram disponibilizados $\mathrm{R} \$ 160$ bilhões em mais de 27 milhões de contratos. É importante destacar que cerca de $30 \%$ destes contratos e do público atingido são de mulheres agricultoras com foco na inclusão sócio produtiva e no protagonismo da mulher (Bianchini, 2015). Segue abaixo dados do Banco Central sobre os valores contratados e a quantidade de contratos no período de janeiro de 2013 a março de 2017: 
Figura 1 - Quantidade e valores dos contratos por região e no Brasil

\subsection{Quantidade e Valor dos Contratos por Regiäo e Brasil}

BANCO CENTRAL DO BRASIL

Periodo. Janeird/2013-Marpo/2017 Ecraids en 2503/2017 16.35

Valores em Reais (RS)

\begin{tabular}{|c|c|c|c|}
\hline Regas & Carl Contratos & Vhar Contrationo (185) & 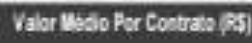 \\
\hline CEITRO-OESTE & 707.652 & $\$ 241987244,74$ & 20120202 \\
\hline SUl & 3424.64 & 230.005 .67 .40 .65 & 2005,18 \\
\hline SUDESTE & 1.86451 & $174.820204075,80$ & serste. \\
\hline NORTE & 44600 & 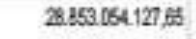 & 6660228 \\
\hline YORDESTE & $3 \pi, 412$ & 5126830046422 & 13500,6 \\
\hline BRASIL & 10.240 .855 & $637.266 .565 .676,05$ & 6223934 \\
\hline
\end{tabular}

Fonte: Banco Central do Brasil, 2017.

A importância do acesso ao crédito para a agricultura familiar, segundo os entrevistados, é fundamental, pois permite uma possibilidade de investimento com juros mais baixos, possibilitando ao agricultor mais competitividade, gerando maiores resultados econômicos e melhorando a qualidade de vida das famílias. Os entrevistados percebem essa política como uma conquista importante que melhorou as possibilidades de investimento nas propriedades e que fomenta a permanência do jovem no campo.

Para o Plano Safra 2016/2017, lançado em abril de 2016, foram desenvolvidas ações e linhas estratégicas de atuação para juventude rural, questões de gênero e incentivos à agroecologia, desenvolvendo linhas específicas e aumentando o recurso destinado para esses trabalhadores rurais. (MDA, 2016). O impacto sobre a sucessão familiar diz respeito a condição de investimentos com juros menores que os de mercado, garantindo, através do seguro agrícola, a renda da família. Além disso, há uma linha de crédito específica para o jovem, denominada PRONAF JOVEM, que é voltada ao acesso ao crédito de pessoas entre 16 e 29 anos.

Mas embora apontem os avanços na oferta do crédito, os entrevistados reconhecem que ainda há muita dificuldade no acesso e aplicação do mesmo, corroborando com os resultados da pesquisa de Guanzirolli (2007), que demonstra a concentração de crédito para agricultores que já possuem uma capacidade produtiva. Aquino e Schneider (2015), evidenciam que desde sua criação houve avanços significativos na aplicação do crédito do Pronaf, mas que ainda não conseguem evidenciar um processo de inclusão e igualdade, pois ainda fomenta um 
tipo de produção rural considerada como "modelo" produtivo. Os autores destacam ainda a necessidade de identificar o impacto do Pronaf a partir do número de empregos gerados e mantidos no meio rural. Embora seja uma política fundamental para o rural brasileiro o Pronaf não conseguiu produzir inovações no processo produtivo (AQUINO e SCHENEIDER, 2015), portanto, seus impactos sobre o processo sucessório podem se resumir a uma continuidade do processo produtivo para uma agricultura tradicional.

Para os entrevistados o agricultor virou "produtor de matéria prima" e "consumidor" (Entrevista SABOR COLONIAL). Esse aspecto diminui sua capacidade de geração de renda, inclusão de novos membros para trabalhar, causa dependência dos atravessadores e ainda dificuldade de quitar os financiamentos feitos para capitalização da propriedade. Considerandose os aspectos citados, é possível observar que os efeitos desta política para produzir sucessão familiar ainda são pequenos.

Com relação ao crédito, também foi sugerido que, para diminuir a limitação dessas políticas é preciso desenvolver formas de subsídio e assistência técnica integrada. De fato, o acesso ao crédito é, além de ser uma conquista dos agricultores, se trata de uma política de incentivos importante, mas que sozinha não é capaz de atender a todas as necessidades que os entrevistados julgam ser causa e consequência da falta de sucessão do meio rural:

Pronaf mesmo, das [...] 4 milhões de famílias só 2 milhões conseguiram acessar. Então nós temos 2 milhões de famílias ainda que não acessam o crédito, por um motivo ou por outro, porque não querem, porque não conseguem, porque não tem terra, porque não tem documento, aquela coisa toda que é hoje um problema do acesso ao crédito. (Entrevista FETRAF)

Além do acesso ao crédito não ser universal, o entrevistado que o mesmo é aplicado com recursos do Pronaf para investimento e custeio de propriedades agrícolas em instrumentos que não são pautados pelos princípios e práticas solidárias, no qual o projeto de desenvolvimento defendido pelas organizações sociais está pautado. Um exemplo é o recurso aplicado na aquisição de defensivos, de sementes transgênicas, práticas estas que contrariam o modelo de desenvolvimento defendido pelas organizações sociais em questão. Nesse aspecto o Pronaf estaria fazendo "mais do mesmo", conforme apontam as pesquisas de Aquino e Schneider (2015). 
Embora não seja problema superado, o acesso ao crédito foi considerado pelos entrevistados um dos maiores avanços para a agricultura familiar, pois permitiu que muitos agricultores pudessem melhorar sua capacidade de produção e absorver mais mão de obra da família. No entanto, há que se considerar que o grau de endividamento das famílias pode desequilibrar a capacidade financeira familiar, ocorrendo um forte debate das organizações sociais sobre a necessidade de aliar o crédito a outras políticas, como processos formativos de educação financeira, crédito orientado para uma boa aplicação dos recursos e discussão de modelos alternativos de produção, para garantir que o recurso aplicado esteja coerente com o modelo de desenvolvimento defendido. Nesse aspecto, também é importante destacar que ao passo que o crédito pode ser um incentivo para permanência do jovem pela sua capacidade de acesso e condições de melhoria da produção, também pode ser um fator de endividamento e, portanto, saída para o trabalho urbano.

A terra, além de patrimônio, é o instrumento de trabalho do agricultor, a sua função social é assegurada pelo Estatuto da Terra (Lei 4.504/64). Entretanto, a democratização do acesso a terra é um dos maiores desafios identificados pelas organizações sociais. O Programa Nacional de Crédito Fundiário (PNCF) surge em 2003, substituindo o Banco da Terra, com a proposta de criar opções de ampliar ou adquirir terras para a produção agrícola. O crédito é destinado aos trabalhadores(as) rurais, seus filhos e estudantes de escolas agrotécnicas, com renda familiar anual de até $\mathrm{R} \$ 15$ mil e patrimônio de até $\mathrm{R} \$ 30$ mil. Estes devem ainda comprovar mais de 5 anos de experiência rural nos últimos 15 anos (MDA, 2016). O Programa possui três linhas de financiamento: - Linha Combate à Pobreza Rural (CPR); Linha Consolidação da Agricultura Familiar CAF; e Linha Nossa Primeira Terra NPT. Esta última é destinada a jovens rurais, filhos e filhas de agricultores, estudantes de escolas agrotécnicas e centro familiares de formação por alternância, com idade entre 18 e 29 anos, que queiram viabilizar o próprio projeto de vida no meio rural. O prazo do financiamento é de até 35 anos para quitar o financiamento, com 3 anos de carência e a taxa de juro de 1,0\% ao ano.

O tamanho da propriedade impacta diretamente na capacidade de produção e de absorver os demais membros da família para que possa dar continuidade à produção familiar. Portanto, os entrevistados entendem que o crédito fundiário surge como resposta a 
necessidade de se implementar linhas de acesso ao crédito para populações de baixa renda. 0 acesso a terra ainda é determinante para a escolha do jovem em permanecer no meio rural. Silvestro et al (2001), indica que grande parte dos jovens não ficam no meio rural porque não veem condições de produzir com a quantidade de terra disponível para a família, portanto, a ampliação dessa terra resultaria numa maior possibilidade de sucessão.

Entretanto, a política de crédito fundiário não é compreendida pelos entrevistados como uma estratégia eficiente, uma vez que os valores destinados à compra são baixos, pela falta de terras com qualidade para produção e ainda há necessidade de créditos para produção, o que gera inadimplência e endividamento do agricultor. Conforme entrevistas, grande parte dos tomadores de crédito fundiário estão inadimplentes, o que é corroborado pelos dados do Governo Federal, pois em 2013 dos 50 mil contratos existentes 16 mil estavam irregulares (mais de 30\%) (BRASIL, 2013). Sobre essa política os entrevistados ressaltam que:

[...] o crédito fundiário não resolve o problema de ninguém. É uma política sem futuro, [...] é um pobre comprando de outro pobre. O crédito fundiário não democratiza a propriedade. [...] sem contar os problemas que tem que muito crédito fundiário que é sítio de final de semana, não é propriedade. (Entrevista MST)

Além disso, os custos para regularização das terras são considerados elevados pelos entrevistados. No caso de transmissão de patrimônio para escriturar ao filho herdeiro, há um valor elevado de custos, que onera o sucessor, dificultando a legalização. Observe-se também que existe uma forte tendência para que os pequenos agricultores adotem modelos de investimento que não são compatíveis em pequenas propriedades, criando dependência de mercado de insumos, de sementes, de tecnologias, que deveriam facilitar o processo produtivo, mas acabam criando uma forte dependência econômica. Portanto, mesmo o crédito tendo sido constituído com uma base solidária, acaba financiando modelos convencionais de produção, não alternativos.

As políticas de crédito, tanto para investimento e custeio da produção quanto para o acesso a terra, são importantes para a sucessão, necessárias para o agricultor, entretanto, , ainda se caracterizam como ações isoladas que não impactam significativamente sobre o processo sucessório. Nesse aspecto, Carneiro e Castro (2007) apontam que as demandas dos 
agricultores devem articular todo o processo produtivo, que resulta em melhoria da renda, acesso e qualidade de vida aos agricultores. Na sequência será abordada a assistência técnica como política que impacta sobre a sucessão familiar no meio rural, tecendo reflexões sobre seus desafios e limitações.

3.2 Assistência técnica e seus impactos sobre a sucessão familiar

Outra política citada pelos entrevistados que deve ser aliada ao crédito para investimento ou aquisição de terra é a política de Assistência Técnica. A Política Nacional de Assistência Técnica Rural (PNATER) foi instituída em 2010 através da Lei n 12.188/2010. Embora exista desde 2003, a PNATER atua através de organizações sociais credenciadas (MDA, 2015).

A assistência técnica é pautada na necessidade de desenvolver ferramentas e instrumentos que qualifiquem o processo produtivo de base familiar, através de atividades de formação, capacitação e acompanhamento a propriedade, apresentando aos agricultores estratégias e tecnologias que melhorem o desempenho produtivo, a renda e a qualidade de vida no campo.

Além de assistir o processo produtivo rural, a PNATER ocupa-se de estimular o agricultor no seu processo formativo a fim de desenvolver sua autonomia a partir dos seus saberes, o que também apareceu como importante preocupação das organizações sociais representativas da agricultura familiar. A apropriação do conhecimento significa o fortalecimento dos agricultores, com foco no processo de gestão da propriedade, aumento da produtividade, respeito ao meio ambiente, entre outros. A assistência técnica hoje, na visão dos entrevistados, está a serviço de um modelo produtivo, mais que do interesse no desenvolvimento de estratégias de desenvolvimento do meio rural e da agricultura familiar. Essa também é a indicação da obra de Renk, Dorigon e Bagnara (2014), que apontam esse fenômeno como resultado do processo de industrialização da região.

A assistência técnica foi, durante muito tempo instrumento para as mudanças ocorridas no processo de produção rural, em especial para indução ao processo de integração e produção 
de matéria prima para a indústria, utilizando-se das características sociais e os recursos naturais da região para o desenvolvimento de estratégias produtivas alinhadas ao grande capital, como aconteceu com a implantação do sistema de integração de suínos e aves (ALBA E SANTOS, 2011).

Outro ponto fundamental é a concepção de que o acesso à assistência técnica e gestão na propriedade rural devem ser mais democráticos e inclusivos, pois ainda há uma concentração do poder representado pelo pai nas tomadas de decisão. Isso tem impacto na permanência do jovem, que vislumbra liberdade e autonomia. Existem estratégias de capacitação técnica para jovens desenvolvidas pela Epagri e pela Fetraf, em especial de projetos políticos. Entretanto, as organizações sociais identificam que ainda há uma dificuldade de implantação dos conhecimentos adquiridos, pois a liberdade e capacidade do jovem na gestão da propriedade ainda é muito questionada pelos pais. Renk, Dorigon e Bagnara (2014) e Brumer (2014), apontam que a hierarquização da organização produtiva reflete sobre a escolha do jovem na permanência ou não, uma vez que há pouca liberdade e debate sobre o processo produtivo, concentrado no pai. A Ater nesses casos também é praticamente destinada ao "chefe" da família, ou seja, ao homem mais velho que detêm todo o poder sobre a organização da propriedade.

Para além da liberdade do jovem, é preciso repensar o processo produtivo como estratégia de desenvolvimento humano, a fim de melhorar a qualidade de vida dos agricultores. Em diversos momentos é reiterada a penosidade do trabalho no meio rural e as doenças causadas pela adesão de um modelo produtivo que satura a vida dos animais, da produção da terra e a saúde do agricultor. A construção de alternativas passa por uma assistência técnica que responda ao projeto de desenvolvimento da agricultura familiar, pois, na percepção das organizações sociais ainda há predomínio de interesses das empresas que detêm tecnologias, das indústrias agroquímicas, as quais, por vezes, a assistência técnica defende e reitera. Portanto, há que se avançar em um modelo de Assistência Técnica de cunho público, independente de processos de submissão e dependência de modelos produtivos hegemônicos, , na medida em que os modelos atuais de Ater estão mais preocupados em representar marcas e interesses econômicos que produzir o desenvolvimento rural. Ainda há pouco investimento 
em pesquisas que diminuam a penosidade do trabalho rural, e as tecnologias disponíveis não são viabilizadas aos pequenos produtores, conforme corrobora a produção de Carneiro e Castro (2007).

Portanto, as políticas de assistência técnica precisam estar mais voltadas à qualidade de vida do agricultor e a manutenção da propriedade se quiserem impactar sobre a sucessão familiar.

3.3 Novas e velhas pautas para as organizações sociais na promoção da sucessão no meio rural

Os entrevistados reconhecem que os avanços alcançados com a implementação de políticas públicas foram fundamentais para que a agricultura familiar continuasse se reproduzindo. Por outro lado, também destacam que a falta de sucessão é uma problemática que evidencia a necessidade de avançar na consolidação dessas políticas. É possível identificar no depoimento que segue, uma constatação importante sobre a necessidade do movimento sindical da agricultura familiar em avançar e rever suas pautas no que diz respeito às políticas públicas, e o quanto a sucessão ainda não configura como questão central nessas pautas.

Então as políticas foram avançando tanto que o próprio movimento sindical já faz avaliação que nós não temos pauta mais. Porque elas foram atendidas e nós, nesse período todo fomos implementando as políticas e não conseguimos, de certa forma, elaborar novas pautas, que possam ser novidades como foi a habitação (Entrevista FETRAF). Na mesma direção afirma o entrevistado da CRESOL: “Hoje a demanda que existe ela é toda atendida, então... a demanda do crédito agrícola, pra toda família, inclusive sobrando né, essa política do governo ela nos atende" (Entrevista CRESOL).

Tais concepções são controversas, haja vista que a reprodução da agricultura familiar ainda apresenta muitos dilemas e desafios, como se pode perceber no Relatório do Conselho Nacional de Desenvolvimento Rural Solidário e Sustentável de 2013. O documento aponta que ainda há muita pobreza no meio rural, e muitas dificuldades na reprodução da agricultura familiar que impactam diretamente na opção ou não dos jovens permanecerem no meio rural. Com relação aos direitos trabalhistas, por exemplo, são importantes questões que levam o 
jovem a optar pelo espaço de trabalho urbano; o método de integração torna o agricultor dependente e subordinado a um sistema de produção com baixas remunerações; ainda existem quatro milhões de agricultores que não tem acesso ao crédito pela dificuldade de oferta de garantias. (CNDRSS, 2013) Ainda é importante destacar as ações que ameaçam os direitos dos trabalhadores rurais, como a caso da reforma da previdência rural. Também identificou-se concepções mais pessimistas dos entrevistados, que questionam a capacidade de continuidade do projeto político da agricultura familiar pela falta de sucessores:

Infelizmente é um tema que só agora está entrando para agenda dos governos e dos movimentos sociais, temo que seja já bastante tarde, para reverter esse quadro do esvaziamento rural, o que tem aí não é suficiente para resolver, para dar conta da permanência desses jovens no meio rural, de uma nova geração de jovens, no meio rural (entrevista pesquisador). Compreende-se que apesar da luta das organizações sociais na região estudada apresentar um protagonismo significativo no que se refere aos movimentos sociais da agricultura familiar, atualmente passaram a assumir uma função mais técnico operativa na operacionalização de políticas públicas em detrimento de uma atuação sociopolítica organizada em pautas comuns.

O roteiro de entrevista proposto indicou que os entrevistados pudessem refletir sobre quais são as problemáticas que motivam a falta de sucessão no meio rural e, posteriormente como as organizações sociais representantes da agricultura familiar têm buscado ações para enfrentamento ou superação dessas problemáticas. Uma grande dificuldade identificada se refere a capacidade de articulação entre as políticas públicas, assim como entre as ações das organizações sociais, uma vez que algumas ações estão sobrepostas e não são complementares. Não há, inclusive, uma pauta que oriente a ação conjunta dessas organizações. Praticamente todas as organizações apontaram que as políticas públicas instituídas estão desarticuladas e a maioria delas indica que existem demandas que ainda não foram atendidas.

Quando as organizações pensam em estratégias para a sucessão no meio rural é preciso pensar além da juventude, é preciso buscar ampliar as oportunidades no meio rural, articulando políticas públicas e as ações das organizações sociais: 
[...] acredito que deva ter uma parceria grande entre todas as essas instituições de trabalhar em prol de um objetivo de qualificar os jovens e mostrar que tem oportunidades. [...] porque não tem como te dizer quais são as ações porque elas são muitas [...]. Hoje a gente percebe que algumas coisas já estão sendo feitas, então o próprio incentivo a moradia rural, promovida por algumas instituições, o Pronaf Jovem, o Pronaf Mulher que também está aí para contribuir, o próprio Pronaf da agricultura familiar com juros baixos. (Entrevista EPAGRI)

Assim, promover a sucessão no meio rural implica em implementar políticas públicas de forma articulada que respondam as diferentes dimensões que envolvem a realidade dos jovens, na intercessão entre trabalho, educação, crédito, gênero, entre outras variáveis. Estas especificidades devem ser pensadas para a juventude rural na sua heterogeneidade e concebidas como um processo de participação protagonizado pelos jovens. Segundo Castro (2009), os jovens são considerados teoricamente como sujeitos chaves para o desenvolvimento rural. A partir dessa afirmação destaca que o protagonismo dos jovens rurais na construção de políticas públicas é fundamental para que a juventude permaneça ou não no meio rural como sujeito responsável pela manutenção e ampliação do patrimônio familiar.

[...] ampliar as políticas públicas pra isso, as que já existem, ter uma política pública específica para o jovem. Um programa de habitação específico da juventude, um crédito específico para juventude, que possa permitir o acesso a vários mecanismos, por exemplo, eu quero um computador, eu vou lá e compro um computador, pronto!(entrevista FETRAF).

Os projetos sociais desenvolvidos pelas organizações sociais, bem como as políticas públicas implementadas são importantes instrumentos para viabilizar a construção do projeto de vida dos jovens, mas isoladamente não conseguem garantir que a sucessão aconteça.

Considerando as potencialidades e fragilidades vivenciadas pelos jovens rurais em suas diferentes trajetórias, que passam pelo acesso e/ou falta de terra, lazer, educação, saúde e recursos de crédito financeiro para investir na propriedade rural, Barcellos (2014), afirma que tais potencialidades ou fragilidades poderiam ser garantidas e/ou supridas através da implementação de programas e políticas públicas efetivas. Ainda segundo o autor, a juventude rural precisa ser considerada como um ator que se articula politicamente, na elaboração, implementação e avaliação de políticas públicas que atendam suas demandas. Nesse sentido, a juventude é um tema transversal, que deve ser abordado no conjunto do escopo das políticas voltadas para a área social. (BARCELLOS, 2014). 
O acesso a educação, habitação, métodos de produção menos penosos e com retorno financeiro mais adequados, valorização dos modos de vida e comunitários, a melhoria de serviços de educação, saúde, lazer e acesso à informação, espaços de socialização e equipamentos sociais coletivos, agregação de valor dos produtos tradicionais e diferenciados, autonomia dos jovens, entre outros, são dimensões que precisam estar articuladas, para que possam estimular a permanência dos jovens rurais e promover ações efetivas de desenvolvimento para o meio rural.

\section{Considerações finais}

A temática da sucessão não deve ser concebida como uma problemática separada das dificuldades que a agricultura familiar encontra para sua reprodução. Pensar a sucessão da juventude no meio rural perpassa pela garantia de direitos previdenciários, de acesso à habitação, de qualidade de vida, de tecnologia para o processo produtivo, de garantia de renda, de possibilidade de convívio comunitário entre outros. Também há que se destacar que a sucessão familiar envolve múltiplos fatores, muitos dos quais não foram foco deste estudo, como os aspectos intra-familiares (renda familiar, quem dirige o empreendimento, divisão do trabalho familiar, entre outros).

Observa-se que as políticas públicas são extremamente importantes e que grande parte das organizações sociais existentes na região Oeste são operadoras dessas políticas. Entretanto, identificou-se que as políticas setorializadas e desarticuladas não resolvem os problemas que se desdobram na ausência de sucessão. É preciso retomar e avançar no diálogo entre o Estado e a sociedade civil sobre as pautas relativas à agricultura familiar e mais especificamente sobre as pautas relacionadas às juventudes rurais. Apontamos como desafios para enfrentar a problemática da sucessão e que devem ser pautas das organizações o apoio e fortalecimento do projeto de desenvolvimento sustentável que estimula a permanência no meio rural, com tecnologia adequada à pequena produção, em menor escala, com diversidade e agroecológica, a fim de fomentar um modelo produtivo alternativo, inclusivo e sustentável ao meio rural; a necessidade urgente de democratização do acesso à terra, com propostas de planejamento 
adequadas a juventude rural e a valorização dos atores sociais, a partir de seus saberes e práticas, como protagonistas na construção de um modelo de sociedade igualitário.

As políticas públicas são ferramentas importantes para a continuidade da agricultura familiar, porém se implementadas de forma desarticulada não são respostas eficientes para que a "nova" juventude rural permaneça na agricultura. Além da intersetorialização das políticas, é preciso avançar para que atuem de maneira estrutural no processo produtivo e na valorização (econômica, cultural, social, ambiental) para o reconhecimento da agricultura familiar em sua diversidade, em sua compreensão e no seu processo produtivo, tornando as relações de trabalho entre os espaços urbano e rural mais justas eigualitárias.

Também se reitera a necessidade de mais estudos e sistematização das práticas que as organizações representativas da agricultura familiar têm vivenciado nesses últimos 40 anos. Essa pesquisa indica que essas organizações sociais são responsáveis pela produção de um capital social importante no que se refere a um protagonismo voltado para a elaboração e implementação de políticas públicas para a agricultura familiar e na construção de um modelo de desenvolvimento mais justo e sustentável. Ou seja, existem experiências consistentes e consequentes sobre a agricultura familiar que precisam ser avaliadas, problematizadas e disseminadas através de um diálogo entre o meio acadêmico e as organizações sociais.

\section{Notas}

1 Existem diversas terminologias utilizadas para descrever a permanência do agricultor no processo produtivo, tais como sucessão familiar, sucessão geracional, sucessão hereditária ou ainda permanência no campo. Neste sentido, assumimos a noção de sucessão na agricultura familiar de Abramovay (1998) e Silvestro (2001), que a definem como a continuidade do processo produtivo de base familiar no patrimônio da família.

2 Este recorte faz parte de dissertação de mestrado defendida em 2016 junto ao Programa de Pós-Graduação Stricto Sensu em Políticas Sociais e Dinâmicas Regionais da Unochapecó. O texto de autoria da primeira autora, conta também com participação das orientadoras.

3 Órgão estatal de apoio à pesquisa e extensão rural que na ocasião da pesquisa desenvolvia um projeto voltado aos jovens no meio rural.

4 Os fundos rotativos são pequenos depósitos comunitários, geridos pelos próprios membros, ou por pequenos fundos sociais que são utilizados para financiar com menor burocracia investimentos produtivos de comunidades. (CRESOL CENTRAL SC/RS). 


\section{Referências}

ABRAMOVAY, Ricardo (coord). Juventude e agricultura familiar: desafios e novos padrões sucessórios. Unesco: Brasília, 1998.

ALBA, Rosa Salete; SANTOS, Verenice Fátima S. dos. Chapecó no contexto da migração campo/cidade. Cadernos do CEOM - Ano 16 no 15 - UNOCHAPECÓ - Junho/2002.

AQUINO, Joacir Rufino de; SCHNEIDER, Sergio. O Pronaf e o desenvolvimento rural brasileiro: avanços, contradições e desafios para o futuro. In: GRISA, Cátia; SCHENEIDER, Sérgio (organizadores). Políticas públicas de desenvolvimento rural no Brasil. Porto Alegre: Editora da UFRGS, 2015. 624 p.

BARCELLOS, Sérgio Botton. A formulação das políticas públicas para a juventude rural no Brasil: atores e fluxos políticos nesse processo social. Tese (Doutorado em CPDA) - Universidade Federal Rural do Rio de Janeiro. Conselho Nacional de Desenvolvimento Científico e Tecnológico, 2014. Disponível em: < http://r1.ufrrj.br/cpda/wpcontent/uploads/2014/10/Tese-Sergio-Botton-Barcellos.pdf>. Acesso em: 24 jun. 2016.

. A juventude rural e as políticas públicas: identidade e reivindicação por direitos sociais. In: MALUF, Renato S; FLEXOR, Georges (Orgs.). Questões agrárias, agrícolas e rurais conjunturas e políticas públicas. 1a ed. E-Papers: Rio de Janeiro, 2017. Disponível em: http://www.e-papers.com.br/produtos.asp?codigo_produto=3002\&promo=1. Acesso em: 31 ago. 2018.

BRUMER, Anita. As perspectivas dos jovens agricultores familiares no início do século XXI. In: RENK, Arlene Anélia; DORIGON, Clovis (orgs). Juventude rural, cultura e mudança social. Chapecó: Argos, 2014.

BIANCHINI, Valter. Vinte anos do Pronaf. 1995-2015 ações e desafios. Brasília: Ministério do Desenvolvimento Agrário, 2015.

BRASIL. Presidência da República. Lei $n^{\circ}$ 11.326/2006. Estabelece as diretrizes para a formulação da Política Nacional da Agricultura Familiar e Empreendimentos Familiares Rurais. Presidente Luiz Inácio Lula da Silva. Brasília, 24 de julho de 2006. Disponível em: <http://www.planalto.gov.br/ccivil_03/_ato2004-2006/2006/lei//11326.htm>. Acesso em: 22 fev. 2015.

CASTRO, Elisa Guaraná. Entre ficar e sair: uma etnografia da construção da categoria jovem rural. Tese de doutorado UFRJ/PPGAS Programa de Pós Graduação em antropologia social. 2005. 
CASTRO, Elisa Guaraná de. Juventude Rural no Brasil: processos de exclusão e a construção de um ator político. Latinoamericana de ciencias sociales. v. 7, n. 1, pp. 179-208, 2009. Disponível em: <http://redalyc.uaemex.mx/redalyc/pdf/773/77307108.pdf> Acesso em: 08 jun. 2016.

CASTRO, Elisa Guaraná de. PNRA e juventude rural: 30 anos depois - balanço e apontamentos em um contexto de ruptura institucional. Retratos de Assentamento. v.19, n.2, 2016. pp. 98124. Disponível em: http://retratosdeassentamentos.com/index.php/retratos/article/view/240. Acesso em: 07 mai.2017.

CARNEIRO, Maria José; CASTRO, Elisa Guaraná. Juventude Rural em Perspectiva. Rio de Janeiro: Mauad X, 2007.

GRISA, Catia; SCHNEIDER, Sergio. Três Gerações de Políticas Públicas para a Agricultura Familiar e Formas de Interação entre Sociedade e Estado no Brasil. RESR. Vol. 52, Supl. 1, p. S125-S146, 2015.

FUNDAÇÃO INSTITUTO BRASILEIRO DE GEOGRAFIA E ESTATÍSTICA - IBGE. Dados do Censo Populacional 2010. Brasília - DF, 2010. MINAYO, Maria Cecília de Souza. O desafio do conhecimento: pesquisa qualitativa em saúde. 12 ed. São Paulo: Hucitec, 2010.

MINISTÉRIO DO DESENVOLVIMENTO AGRÁRIO, Conselho Nacional de Desenvolvimento Rural Sustentável (CNDRS/CONDRAF). Documento de referência. $2^{\circ}$ Conferência nacional de desenvolvimento rural sustentável e solidário. Brasília, abril/2013.

MINISTÉRIO DO DESENVOLVIMENTO AGRÁRIO, Conselho Nacional de Desenvolvimento Rural Sustentável (CNDRS/CONDRAF). Política de Desenvolvimento para o Brasil Rural. Brasília, 2010.

MINISTÉRIO DO DESENVOLVIMENTO AGRÁRIO. Mais inovação na agricultura familiar. Disponível em:http://www.mda.gov.br/sitemda/noticias/mais-inova\%C3\%A7\%C3\%A3o-naagricultura-amiliar\#sthash.FdsxKplJ.dpuf. Acesso em: 19 dez. 2016.

MINISTÉRIO DO DESENVOLVIMENTO AGRÁRIO. Plano Safra da Agricultura Familiar 2014/2015 - Alimentos para o Brasil. Disponível em:

http://www.mda.gov.br/portalmda/sites/default/files/user_arquivos_278/cartilha_0.pdf. Acesso em: nov. 2016.

MINISTÉRIO DO DESENVOLVIMENTO AGRÁRIO. Plano Safra da Agricultura Familiar 2016/2017 - Alimentos saudáveis para o campo e para cidade. Disponível em: http://www.mda.gov.br/sitemda/sites/sitemda/files/cartilha_plano_safra_2016.pdf. Acesso em: mai. 2016. 
RENK, Arlene Anélia. Sociodicéia às avessas. Chapecó, SC: Grifos, 2000.

RENK, Arlene Anélia; DORIGON, Clovis (orgs). Juventude rural, cultura e mudança social. Chapecó: Argos, 2014.

RENK, Arlene; DORIGON, Clóvis; BAGNARA, Maritânia. Juventude rural e mudança social. In: RENK, Arlene Anélia; DORIGON, Clovis (orgs). Juventude rural, cultura e mudança social. Chapecó: Argos, 2014.

SILVESTRO, Milton et al. Os impasses sociais da sucessão hereditária na agricultura familiar. Florianópolis: Epagri; NEAD: Brasília/Ministério do Desenvolvimento Agrário, 2001, 120 p. 